\title{
Comparison of rhythmic and non-rhythmic aerobic exercises on depression and balance in the elderly
}

\author{
II-Ho Kwon ${ }^{a}$, Jun-Young Song ${ }^{a}$, Do-Ye Kim ${ }^{a}$, Je-Yeong Son ${ }^{a}$, Yu-Jin Shim ${ }^{b}$, Won-Seob Shin ${ }^{a, b}$ \\ ${ }^{a}$ Department of Physical Therapy, College of Health and Medical Science, Daejeon University, Daejeon, Republic of Korea \\ ${ }^{b}$ Department of Physical Therapy, Graduate School of Health and Medicine, Daejeon University, Daejeon, Republic of Korea
}

\begin{abstract}
Objective: The purpose of this study was to investigate the effects rhythmic and non-rhythmic aerobic exercises on depression and balance of healthy elderly people.

Design: Randomized controled trial.

Methods: Nineteen older subjects were randomly divided into 2 groups for rhythmic and non-rhythmic aerobic exercises. Both aerobic exercises consisted of functional movements such as turning in opposite directions, and running in place, the exercise consisted of movements that could activate balance. The rhythmic training group initially used music with 8 beats, and then later progressed to 16 beats. Additionally, we adjusted the pace of the music using songs from 125 beats per minute (bpm) to $160 \mathrm{bpm}$. Both groups were exercised for 50 minutes a day, twice a week, for a total of 8 weeks. We measured the condition of the patients before the intervention, and after 8 weeks of intervention. The Beck depression inventory (BDI) was used to measure the degree of depression. The Berg balance scale (BBS) was used to measure static and dynamic balance ability. We measured the subject's subjective balance confidence using the fall efficacy scale (FES).
\end{abstract}

Results: Both groups showed significant improvement in BDI, BBS, and FES $(p<0.05)$. The rhythmic aerobic exercise group showed a significant improvement only in the BBS change values compared to the non-rhythmic group $(p<0.05)$.

Conclusions: According to this study, both rhythmic and non-rhythmic aerobic exercises resulted in significant improvement in the degree of depression and balance ability of the elderly. The rhythmic aerobic exercise was more effective for dynamic balance ability.

Key Words: Aerobic exercise, Depression, Postural balance

\section{Introduction}

As the population grows older in age, the overall functional decline occurs in several systems, including cardiovascular, musculoskeletal, and metabolic systems [1]. In particular, the reduction of skeletal muscle due to aging limits the activities of daily living, task performance and leisure activities, resulting in decreased motility, increased risk of falling, increased functional dependency, and lowered quality of life [2]. Approximately one-third of the elderly experience falls each year, and as the age increases, the fall rate increases $[3,4]$. Falls are affected by gender, cohabitation, presence of illness, emotional depression, exercise, and smoking [5], and it reduces self-confidence in activity and balance performance for daily life [6]. It also limits walking [7] and causes other fear of falling, limiting the elderly's independence [8]. As a result, aging-induced musculoskeletal weakness impairs functional movements and increases the risk of falls and thus the risk of death [9]. Therefore, improvement of balance ability of the elderly for fall prevention is also important for maintenance of daily life movement [3].

In previous studies, there were many exercise intervention methods to improve the function and balance ability

Received: 26 August, 2017 Revised: 17 September, 2017 Accepted: 18 September, 2017

Corresponding author: Won-Seob Shin

Department of Physical Therapy, Graduate School of Health and Medicine, Daejeon University, 62 Daehak-ro, Dong-gu, Daejeon 34520, Republic of Korea Tel: 82-42-280-2294 Fax: 82-42-280-2295 E-mail: shinws@dju.kr

(c) This is an Open-Access article distributed under the terms of the Creative Commons Attribution Non-Commercial License (http://creativecommons.org/licens es/by-nc/4.0) which permits unrestricted non-commercial use, distribution, and reproduction in any medium, provided the original work is properly cited.

Copyright ( 2017 Korean Academy of Physical Therapy Rehabilitation Science 
of the elderly. Exercise methods include strengthening exercise using elastic bands [10-12], aerobic exercise [13], and programs that combine fall prevention education and exercise [14]. A group with regular functional exercise was effective in improving balance ability to prevent falls in the long term [15], and actually lowered the incidence of falls $[16,17]$. In addition, it has been shown in several previous studies that training through functional exercise has positive effects on not only the body but also the psychological component in the elderly $[12,13,15]$.

Aerobic exercise has been applied to the elderly as a safe and effective exercise method, and is effective in preventing and reducing the deterioration of daily life physical fitness and cognitive function [18]. Aerobic exercise also improved physical functions such as lower extremity muscle strength, muscle endurance, flexibility and balance [19], and depression [20]. It has been shown that exercise programs with rhythmic motion have a greater effect on improving physical fitness than general muscle strength-aerobic exercise [21]. More than $30 \%$ of the elderly suffer from depression, which is highly correlated with falls [22], and is a factor that reduces self-esteem and quality of life [23]. With the case of depression, participation in a rhythmic exercise program has the effect of stabilizing the emotions [24], and as participation in regular exercise increases, a more positive influence on body function can be observed, which subsequently raises life satisfaction [25].

Based on previous studies, aerobic exercises are an effective for the elderly, and the integration of rhythmic motion has a positive effect on not only the physical health but also the emotional health component of the elderly [18-20]. de Dreu et al. [26] stated that movements rhythmic movements can be used to mediate dancing, such as the tango or the waltz, as an intervention or that music can be added to existing therapy, and although functional movements for daily life activities are composed of rhythmic patterns, there are no studies that have investigated balance abilities related to falls of the elderly population. Therefore, the purpose of this study was to investigate the effect of rhythmic exercise on depression and balance abilities of the elderly.

\section{Methods}

\section{Participants}

Out of the healthy elderly people using welfare facilities in Daejeon Metropolitan City, elderly women who had met the selection criteria were included in this study. The selection criteria of subjects were those who were aged 65 and over, those who could live and walk independently, and had the mini mental status examination of Korean version (MMSE-K) score of 24 or higher. The exclusion criteria of the subjects were those who had an orthopedic disease or those who had neurological disorders that could affect their balance ability, all of which could affect the outcome of the study. Out of 25 potential participants, 4 participants did not meet the selection criteria and 2 people had wished to withdraw from the study. This study was in accordance to the Helsinki Declaration for ethical principles for medical research on human subjects. After the participants had provided their informed consents after being fully informed of

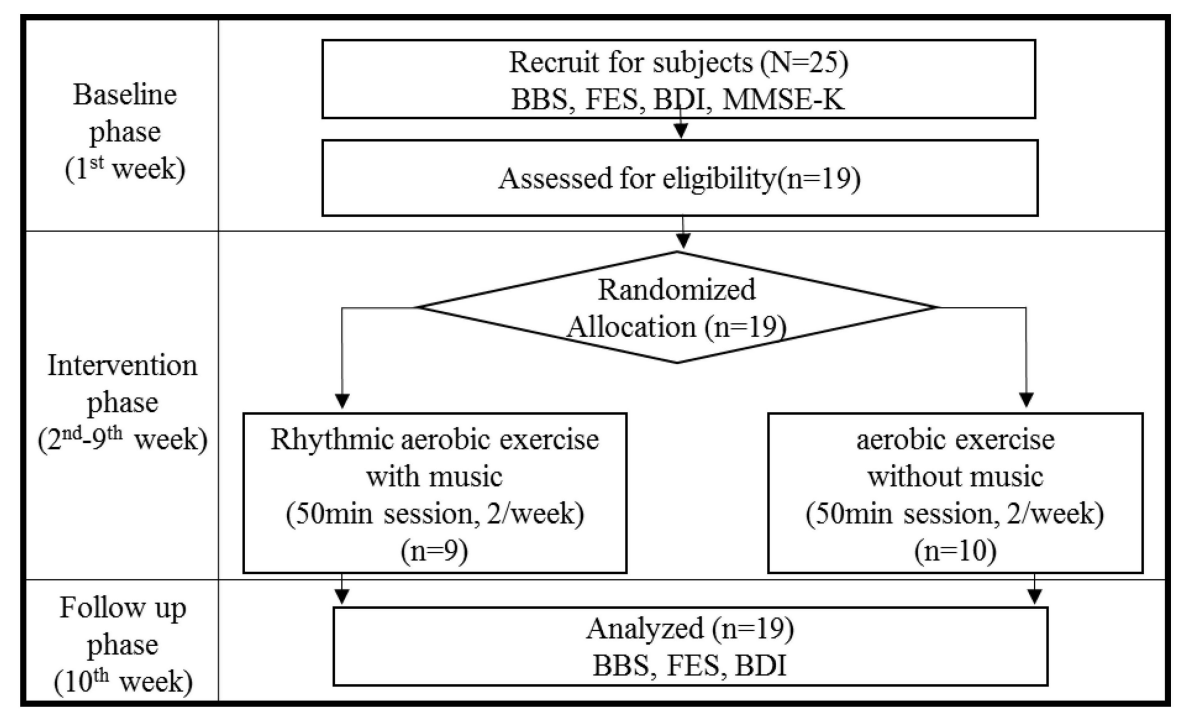

Figure 1. Flow of this study and participants through the program. BBS: Berg balance scale, FES: fall efficacy scale, BDI: Beck depression inventory, MMSE-K: the mini mental status examination of Korean version, min: minutes. 
the purpose, method, and predicted outcomes, and potential dangers of the study, the research process was initiated.

\section{Procedure}

A total of nineteen subjects were randomly divided into either the rhythmic aerobic exercise group $(n=9)$ or the non-rhythmic aerobic exercise group $(n=10)$. The intervention was performed for 50 minutes, twice a week, for a total of 8 weeks, and the same therapist evaluated for depression and balance ability of the subjects prior to and after the intervention. The training program consisted of 10 minutes of preparatory exercise, 30 minutes of exercise, and $10 \mathrm{mi}$ nutes of restorative exercise in both groups (Figure 1). The 2 groups performed exercises that consisted of the same functional movements. The configuration of the functional movements included moving the foot in right and left as well as up and down directions, rotating in place, stretching both legs in diagonal direction, walking while performing lunches, side steps, squats, and running in place to enhance muscle strength and balance maintenance ability. The rhythmic aerobic group performed rhythmically by associating motions with the music. The rhythmic aerobic group initially used music with 8 beats, and then later progressed to 16 beats. Initially during the first week, exercise was performed in accordance to music with approximately 125 beats per minute (bpm) was used, and the bpm was increased by 10 to 15 bpm every week. During the final week, exercise was performed in accordance with music that consisted of 160 bpm. The non-rhythmic aerobic group performed the same functional movements by set for each single action.

\section{Outcome measures}

\section{Depression evaluation}

The effects of exercise on depression were measured using the Beck depression inventory (BDI). It is a questionnaire evaluation composed of 21 questions that can measure the degree of depression. It is an evaluation method designed for individuals aged 13 years or older. This tool has a test-retest reliability of 0.96 and validity of $r=0.83$ [27].

\section{Balance ability evaluation}

Balance ability was assessed in terms of functional balance and subjective balance self-confidence levels.

Balance ability was assessed using the Berg balance scale (BBS). There are 14 items such as sitting, standing, and postural changes, which can be used to objectively evaluate static balance and dynamic balance ability. There are 0 to 4 points for each item and 56 points for the maximum score [28]. In addition, according to Korean studies, An et al. [29] mentioned that the sensitivity of the receiver operating characteristic curve analysis can be used as a useful tool for assessing the risk of falls in the elderly population $(80 \%$, specificity $=75 \%$ ) [30]. This tool has a validity of 0.85 and reliability of 0.92 [31].

The fall efficacy scale (FES) was used to subjectively evaluate the confidence levels of the subjects in regards to falls. The questionnaire evaluation method asks subjects to personally assess their degree of self-assurance that he or she will not fall, and the higher the score, the higher the fall efficacy. The reliability and validity of this tool is 0.959 and 0.972 , respectively [32].

\section{Data and statistical analysis}

Data analysis was performed with IBM SPSS Statistics ver. 22.0 (IBM Co., Armonk, NY, USA). The general characteristics of subjects were obtained by using descriptive statistics, and the Shapiro-Wilks test was conducted to verify the normality and standard deviation. To investigate the effect of training in each group, the paired t-test was conducted, and an independent t-test was used to compare the intergroup training effects. Statistical significant was set at 0.05 .

Table 1. The general characteristics of all subjects

$(\mathrm{N}=19)$

\begin{tabular}{lcrr}
\hline \multicolumn{1}{c}{ Characteristic } & Rhythmic aerobic exercise group $(\mathrm{n}=9)$ & Non-rhythmic aerobic exercise group $(\mathrm{n}=10)$ & $\mathrm{t}(p)$ \\
\hline Age $(\mathrm{yr})$ & $75.33(5.32)$ & $74.40(3.24)$ & $0.468(0.98)$ \\
Weight $(\mathrm{kg})$ & $55.11(9.06)$ & $59.20(4.50)$ & $-1.267(0.23)$ \\
Height $(\mathrm{cm})$ & $150.44(5.68)$ & $155.60(4.53)$ & $-2.199(0.78)$ \\
MMSE-K (score) & $28.33(1.50)$ & $27.60(1.71)$ & $0.988(0.79)$ \\
\hline
\end{tabular}

Values are presented as mean (SD).

MMSE-K: The mini-mental status examination of Korean version. 


\section{Results}

\section{General characteristics of the subjects}

There were no significant differences in age, height, weight, and MMSE-K scores between the 2 groups (Table 1).

\section{Pre- and post-change of depression}

The rhythmic aerobic exercise and non-rhythmic aerobic exercise group both showed a significant reduction in BDI scores from $15.78 \pm 12.57$ points to $7.89 \pm 9.03$ points and from $8.00 \pm 7.33$ points to $3.70 \pm 2.98$, respectively, after the intervention $(p<0.05)$. However, the difference between the two groups was not statistically significant (Table 2).

\section{Changes in balance ability pre-post intervention}

BBS scores of the rhythmic aerobic exercise group increased significantly from $48.56 \pm 4.95$ to $53.22 \pm 3.35$ points after the intervention. BBS scores of the non-rhythmic aerobic exercise group also significantly increased from $50.80 \pm 2.10$ to $53.10 \pm 0.99$ points after the intervention $(p<0.05)$. When comparing the change values of the two groups, there was a significant increase in the rhythmic aerobic exercise group ( $p<0.05$; Table 2$)$.

The rhythmic aerobic exercise group showed a significant decrease in FES scores from $33.11 \pm 30.32$ to $27.89 \pm 27.48$ points after the intervention, and the non-rhythmic aerobic exercise group also showed a significant decrease in FES scores from $16.20 \pm 16.90$ to $10.20 \pm 12.52$ points after the intervention $(p<0.05)$. The FES change values between the two groups were not statistically significant (Table 2).

\section{Discussion}

The purpose of this study was to investigate the effect of an exercise program consisting of rhythmic and non-rhythmic functional exercises to promote balance and daily life motions of elderly people on depression and balance.

There was a significant difference in the depression scores between the rhythmic aerobic exercise group and the non-rhythmic aerobic exercise group $(p<0.05)$. This is consistent with a study by Son et al. [33], in which music-based exercise programs were effective in reducing depression, and Han et al. [18]'s study in which 12 weeks of rhythmic aerobic exercise was effective in reducing depression in the elderly. Music-based programs in rhythmic aerobic exercise play an important role as an emotional means of treatment of balance and gait [34]. In the non-rhythmic aerobic exercise group, the effect of functional training appears to have led to the improvement of physical function, which in turn, may have reduced the emotional depression.

The BBS is an assessment for static and dynamic balance and there was a significant change in BBS scores in both the rhythmic aerobic group and the non-rhythmic aerobic groups. Lee et al. [35] reported that BBS has a high correlation with falls and that is an appropriate tool to be used for early prediction of fall incidences for the elderly who are at high risk of falls. In particular, out of the BBS evaluation items, the one-legged stance and walking with arms spread

Table 2. Comparison of depression and balance between two groups

\begin{tabular}{lcrr}
\hline \multicolumn{1}{c}{ Variable } & Rhythmic aerobic exercise group $(\mathrm{n}=9)$ & Non-rhythmic aerobic exercise group $(\mathrm{n}=10)$ & $\mathrm{t}(p)$ \\
\hline Beck depression inventory & & & \\
Pre-test & $15.78(12.57)$ & $8.00(7.33)$ & $1.62(0.11)$ \\
Post-test & $7.89(9.03)$ & $3.70(2.98)$ & $1.33(0.18)$ \\
Change value & $7.89(5.30)$ & $4.30(5.79)$ & $-1.73(0.10)$ \\
$\mathrm{t}(p)$ & $4.46(0.00)$ & $2.35(0.04)$ & $-1.26(0.21)$ \\
Berg balance scale & & & $0.11(0.91)$ \\
Pre-test & $48.56(4.95)$ & $50.80(2.10)$ & $2.29(0.04)$ \\
Post-test & $53.22(3.35)$ & $-2.10(0.99)$ & \\
Change value & $-4.67(2.96)$ & $-5.44(0.00)$ & $1.34)$ \\
$\mathrm{t}(p)$ & $-4.73(0.00)$ & & $1.52(0.15)$ \\
Falls efficacy scale & & $16.20(16.90)$ & $1.77(0.09)$ \\
Pre-test & $33.11(30.32)$ & $10.20(12.52)$ & $0.41(0.69)$ \\
Post-test & $27.89(27.48)$ & $6.00(7.99)$ & $2.38(0.04)$ \\
Change value & $5.22(3.53)$ & & \\
$\mathrm{t}(p)$ & $4.44(0.00)$ & & \\
\hline
\end{tabular}

Values are presented as mean (SD). 
apart are especially known to be an important factor in evaluating balance [36]. In this study, it is considered that BBS scores were significantly improved in both groups after the intervention since both groups had performed functional movements of the foot and upper and lower extremity stretches. However, when comparing the change values, the rhythmic aerobic training group showed greater improvements. This may have been due to the fact that the tempo of the music was increased every week, which had provided a more dynamic balance training effect compared with the non-rhythmic aerobic training group, resulting in a difference in dynamic balance scores on the BBS.

Both groups showed significant improvements in BBS and FES scores. This suggests that the improvement of balance function is affected by psychological self-confidence. Having psychological anxiety about falling actually results in a decrease in balance ability, which indicates that the physical function and the psychological state are connected and they work together [37]. Particularly, in the rhythmic aerobic training group, it is considered that the addition of music created an even greater amount of emotional and psychological influence. This is supported by the results previous studies by Son and Bang [38] and Kim et al. [39] who showed higher self-efficacy in regards to falls with the addition of music to the intervention.

According to the results of this study, it was observed that when functional movements were applied rhythmically, there was a greater positive influence on static and dynamic balance ability when comparing the change values of the two groups. However, there was no difference between the groups in terms of emotional evaluation variables for depression and efficacy of falls. Lucas et al. [40] reported as the physical activity of the elderly increases, the depression levels decreased. Therefore, as the two groups, who initially had low physical activity levels, participated in greater amounts of physical activity, the degree of depression was significantly decreased in both groups, which may be the reason why there was no significant difference in BDI and FES scores between the two groups.

This study had confirmed that when rhythmic and non-rhythmic aerobic exercises were applied, all elderly subjects showed significant improvements in depression levels and balance ability, and that the rhythmic aerobic exercises were more effective on improving balance ability. However, since this study only included female subjects, further studies should include elderly male subjects who are not accustomed to rhythmic movements to observe if the same effects are observed. In addition, since the improvement of balance ability is related with the speed of the rhythmic movements, it is necessary for further studies to investigate the effects of the various paces used for exercise performance on balance ability. Based on this study, the clinical use of rhythmic exercises for improving balance ability for fall prevention and reducing depression levels in the elderly population is highly anticipated.

\section{Conflict of Interest}

The authors declared no potential conflicts of interest with respect to the authorship and/or publication of this article.

\section{References}

1. Lee SE. An actual study of exercise prescription for the elderly [PhD dissertation]. Seoul: Sungshin Women's University; 2009.

2. Hughes VA, Frontera WR, Wood M, Evans WJ, Dallal GE, Roubenoff $\mathrm{R}$, et al. Longitudinal muscle strength changes in older adults: influence of muscle mass, physical activity, and health. J Gerontol A Biol Sci Med Sci 2001;56:B209-17.

3. Rubenstein LZ, Josephson KR. Falls and their prevention in elderly people: what does the evidence show? Med Clin North Am 2006;90:807-24

4. Jeon MJ, Jeon HS, Yi CH, Cynn HS. Comparison of elderly fallers and elderly non-fallers: balancing ability, depression, and quality of life. Phys Ther Korea 2014;21:45-54

5. Yeom JH, Na HJ. Risk factors of falls among Korean elderly. J Korea Gerontol Soc 2012;32:577-92.

6. Nelson ME, Layne JE, Bernstein MJ, Nuernberger A, Castaneda $\mathrm{C}$, Kaliton D, et al. The effects of multidimensional home-based exercise on functional performance in elderly people. J Gerontol A Biol Sci Med Sci 2004;59:154-60.

7. Cho KH, Lee WH. Changes of spatio-temporal gait parameters according to experience falls in post-stroke patients. Phys Ther Rehabil Sci 2012;1:22-7.

8. Sattin RW. Falls among older persons: a public health perspective. Annu Rev Public Health 1992;13:489-508.

9. Visser M, Schaap LA. Consequences of sarcopenia. Clin Geriatr Med 2011;27:387-99.

10. Choi SW, Lee JS, Ku HJ, Lee DT. Effects of resistive and balance training on walking patterns in the falls experienced elderly women. Korean J Phys Educ 2005;44:287-95.

11. Bae J, Cho SI. Effects of community-based comprehensive fall prevention program on muscle strength, postural balance and fall efficacy in elderly people. J Korean Acad Nurs 2014;44:697-707.

12. Kang KS. The effects of the fall prevention exercise program focussed on activity of daily living, fear of fall and quality of life for the senior citizen center elderly. J Korea Acad Indust Coop Soc 2016;17:267-72.

13. Shigematsu R, Chang M, Yabushita N, Sakai T, Nakagaichi M, Nho H, et al. Dance-based aerobic exercise may improve indices 
of falling risk in older women. Age Ageing 2002;31:261-6.

14. Shin JS, Kim YK, Kang MA, Yeo HN. Effects of fall prevention program on muscle strength, postural balance, and fear of falling in elderly. J Korean Clin Nurs Res 2016;22:10-9.

15. Freiberger E, Häberle L, Spirduso WW, Zijlstra GA. Long-term effects of three multicomponent exercise interventions on physical performance and fall-related psychological outcomes in community-dwelling older adults: a randomized controlled trial. J Am Geriatr Soc 2012;60:437-46.

16. Grahn Kronhed AC, Hallberg I, Ödkvist L, Möller M. Effect of training on health-related quality of life, pain and falls in osteoporotic women. Adv Physiother 2009;11:154-65.

17. Nelson ME, Rejeski WJ, Blair SN, Duncan PW, Judge JO, King AC, et al. Physical activity and public health in older adults: recommendation from the American College of Sports Medicine and the American Heart Association. Circulation 2007;116: 1094-105.

18. Han JH, Lee JE, Park JH, Lee SH, Kang HS. Effect of a 12 week-aerobic exercise program on physical fitness, depression, and cognitive function in the elderly. Exerc Sci 2014;23:375-85.

19. Jung SH, Chung KH. The effects of aerobic exercise therapy on physical functions in the elderly. J Korean Acad Community Health Nurs 2010;21:252-62.

20. Yang SH. The effects of rhythmic airobic exercise on the elderly's depression. Korea Entertain Indust Assoc 2012;11:138-41.

21. Kang HJ, Kim SB, Lee BK. Effects of rhythmic exercise and strengthening-aerobic exercise on physical fitness and MVAS in older females. J Kinesiol 2013;15:1-14

22. Nam IS, Yoon HS. An analysis of the interrelationship between depression and falls in Korean older people. J Korea Gerontol Soc 2014;34:523-37.

23. Lee JW, Hwang SJ. Effects of balance imagery of semi-tandem stance on a flat floor and balance beam for postural control: a comparison between older and younger adults. Phys Ther Rehabil Sci 2015;4:87-93.

24. You OK, Pack SH. The effect of aerobic dance participation on the changes in the daily stress of old women. Off J Korean Soc Dance Sci 2015;32:103-12.

25. Shin MJ, Shim YS. The influence of old people's exercise participation on depression: the function of mediational variables. Korea Soc Wellness 2016;11:327-39.

26. de Dreu MJ, van der Wilk AS, Poppe E, Kwakkel G, van Wegen EE. Rehabilitation, exercise therapy and music in patients with Parkinson's disease: a meta-analysis of the effects of musicbased movement therapy on walking ability, balance and quality of life. Parkinsonism Relat Disord 2012;18 Suppl 1:S114-9.

27. Sprinkle SD, Lurie D, Insko SL, Atkinson G, Jones GL, Logan
$\mathrm{AR}$, et al. Criterion validity, severity cut scores, and test-retest reliability of the Beck Depression Inventory-II in a university counseling center sample. J Couns Psychol 2002;49:381-5.

28. Bogle Thorbahn LD, Newton RA. Use of the berg balance test to predict falls in elderly persons. Phys Ther 1996;76:576-83; discussion 584-5.

29. An SH, Kim WG, Lee BK. The predictive validity of the TUG, BBS, FRT, OLST of falls risk in elderly patient. J Spec Educ Rehabil Sci 2013;52:239-53.

30. Jung DK, Chung Y. The effect of hip joint strengthening exercise using proprioceptive neuromuscular facilitation on balance, sit to stand and walking ability in a person with traumatic brain injury: a case report. Phys Ther Rehabil Sci 2017;6:96-104.

31. Godi M, Franchignoni F, Caligari M, Giordano A, Turcato AM, Nardone A. Comparison of reliability, validity, and responsiveness of the mini-BESTest and Berg Balance Scale in patients with balance disorders. Phys Ther 2013;93:158-67.

32. An SH, Sin HH, Cho HY, Lee GC. The reliability and validity of the falls efficacy scale (Korean version) in stroke patients. J Spec Educ Rehabil Sci 2012;51:363-81.

33. Son BY, Bang YS, Hwang MJ, Oh EJ, Bang JH. The effects of physical functions and depression on quality of life according to fall prevention exercise-applying Otago exercise program with music. J Korea Entertain Indust Assoc 2016;10:113-25.

34. Kim HS, Kwon OY, Lee HJ. Comparison of balance and gait between fallers and non-fallers in elderly. Phys Ther Korea 2002;9: $1-15$.

35. Lee HJ, Yi CH, Yoo EY. Correlations among the berg balance scale, gait parameters, and falling in the elderly. PhysTher Korea 2002;9:47-66.

36. Kim HS, Kwon OY, Lee HJ. Comparison of balance and gait between fallers and non-fallers in elderly. Phys Ther Korea 2002;9: $1-15$.

37. Legters K. Fear of falling. Phys Ther 2002;82:264-72.

38. Son BY, Bang YS. The effect of Otago exercise program on physical function, fall efficacy and fear in falling of stroke patients. J Korea Entertain Indust Assoc 2014;8:187-97.

39. Kim OH, Lee EK, Kim EM. Effects of fall prevention program on fall efficacy scale and activities-specific of balance confidence scale in rural residents. J Korean Public Health Nurs 2011;25:187-96.

40. Lucas M, Mekary R, Pan A, Mirzaei F, O'Reilly EJ, Willett WC, et al. Relation between clinical depression risk and physical activity and time spent watching television in older women: a 10-year prospective follow-up study. Am J Epidemiol 2011;174: 1017-27. 